\title{
PRICE TRANSMISSION AND MARKET INTEGRATION: A TEST OF THE CENTRAL MARKET HYPOTHESIS OF GEOGRAPHICAL MARKETS FOR CASSAVA PRODUCTS IN NIGERIA
}

\author{
C. EZEDINMA, N. M. NKANG AND S. E. IBANA
}

(Received 3, July 2008; Revision Accepted 24, November 2008)

\begin{abstract}
In the wake of the immediate past administration, the Federal Government had demonstrated its concern in making cassava a major industrial raw material and foreign exchange earner. This leads directly to not only measures of expanding cassava production but to improvements in marketing efficiency of the traditional food market of cassava products in the country as well, since inefficiency in the marketing system can lead to unprofitable arbitrage, with attendant welfare losses. With this in mind, this paper investigates price transmission and market integration of cassava products namely chips, chunks, white gari and yellow gari between a central market in Kano and peripheral/rural markets in Taraba, Benue, Nasarawa and Edo States, using standard econometric methods. Precisely, the co-integration methodology was followed. Results show that the markets for all the products were integrated except for chips in Benue, white gari in Nasarawa, yellow gari in Benue, and yellow gari in Edo. Further results indicate that price transmission elasticities range from 0.434 to 1.00 , indicating full transmission in some cases and not in others, while the speeds of price transmission range from $11.46 \%$ to $47.15 \%$, implying that the speed with which cassava product prices are spatially transmitted between the locations is generally low. Improvements in road network and other communication infrastructure will reduce inefficiencies in the traditional cassava product marketing system with attendant gains for producers, middlemen and consumers.
\end{abstract}

KEY WORDS: Cassava, market integration, transmission elasticity, cointegration, arbitrage

\section{INTRODUCTION}

Nigeria grows more cassava than any other country in the world, and cassava production is concentrated in the hands of numerous smallholder farmers located primarily in the south and central regions of Nigeria. According to Nweke et al (2002), a significant proportion of cassava growers in Nigeria have made the transition from traditional production systems to the use of high yielding varieties and mechanization of processing activities. The wide-scale adoption of high yielding varieties and the resulting increase in yield is gradually shifting the problem of the cassava sector from supply (production) to demand issues such as finding new uses and markets for cassava, even though farmers are yet to attain the desired technical efficiency in production due to a lack of other improved inputs like fertilizers and herbicides (see, for example, Ezedinma et al, 2006a).

Granted that cassava supply has been increasing since government intervened in the sector in 2002, government reasoned that an evolution of an industrial raw materials/export market from the predominantly traditional food market would adequately address demand problems. It views this evolution as a development strategy that can spur growth by increasing employment and foreign exchange earnings through export of processed cassava products. This proposed evolution, however, is not without implications. This is because interfacing between the traditional food and industrial raw materials/export market would have consequences for food security, farm structure, rural incomes as well as labour supply. Equally important are the challenges that the transition might have to contend with, which according to Knipscheer et al (2004) include: (i) establishing cost-effective raw material supply systems; (ii) competition of cassava-based farming systems in a broader context: domestically and internationally between cassava and cereals (feed grains, wheat, corn) and their derivates (starch, ethanol, glucose syrups, etc); (iii) cost-competitiveness and efficiency of an infant industry.

Presently, most of the cassava grown in Nigeria is processed and sold through traditional market channels for food commodities. There are several cassava markets that support the traditional food needs of the ever-increasing population, especially the urban population. A wide range of traditional forms of cassava is produced and marketed, mainly by small informal actors organised in informal supply chains in these rural and urban markets (Ezedinma et al 2006c; Nweke 1995; Bokanga and Tewe, 1995). In view of the renewed emphasis on cassava production, processing and marketing in Nigeria, it becomes necessary to investigate whether these rural and urban markets for cassava products are integrated since literature has shown that if prices in geographical markets are not cointegrated, arbitrage between such markets might become unprofitable and some markets may become isolated thus having implications for market efficiency

C. Ezedinmas, International Institute of Tropical Agriculture, Ibadan, Oyo State, Nigeria

N. M. Nkang, Department of Agricultural Economics and Extension, University of Calabar, P. M. B. 1115, Calabar-Nigeria

E. Ibana, Department of Agricultural Economics and Extension, University of Calabar, P. M. B. 1115, CalabarNigeria 
with attendant welfare losses. This implies that if the traditional food market for cassava is efficient, the evolution of an industrial raw materials market might not have the supposed adverse effects on the food supply chain.

Consequently, the objective of this paper is to assess price transmission and market integration in traditional cassava food products between the major urban (demand) market in Kano and rural supply markets located in Benue, Edo, Nasarawa and Taraba States in Nigeria, with a view to providing useful results that would help to balance the interface between the two cassava markets. The sequence of this paper is simple. The methodology, which highlights the data source and analytical techniques, is presented in what follows. Next, we present the results and discussion, and then the paper is concluded in the last section, with policy suggestions.

\section{METHODOLOGY The Data}

This study made use of weekly price data obtained from www.cassavabiz.org, a website owned by the Integrated Cassava Project (ICP) of the International Institute of Tropical Agriculture (IITA). The data spans week 37 in 2004 to week 20 in 2006. The delimitation of the States as per supply and demand markets for cassava products is based on a two-phase nationwide survey by the IITA (see for instance, Ezedinma et al 2006b).

The first phase involved a survey of all the major urban markets in Nigeria from where the major cassava demand markets were chosen. Information on the major cassava products supplied to the markets and their respective source (supply) markets, among others, were obtained using a questionnaire administered to participants in the market who belonged to various cassava products market associations. The major cities that were surveyed in the different zones of Nigeria include: Aba, Calabar, Enugu, Owerri, Onitsha, and Port Harcourt, in the South East zone; Abeokuta, Benin City, Ibadan, Ilorin, Lagos, and Warri, in the South West zone; Abuja, Jos, Lokoja, Lafia, Markurdi, and Kaduna in the North Central zone; Bauchi, Maiduguri and Yola, in the North East zone and Birnin Kebbi, Kano, Katsina, Minna, Sokoto, Zaria, in the North West zone.

The list of rural markets, on the other hand, was compiled from the inform ation obtained from the second phase of the study, which involved a survey of all the listed rural (supply) markets. Key informants identified in the rural markets provided information on the movement of different cassava commodities from the rural market to each urban destination (demand) market.

Following earlier field surveys by Ezedinma et al (2006b), the Kano (Dawanau) market has been found to be a major cross border trade corridor in cassava and other agricultural produce from Nigeria to the Sahelian countries of Bukina Faso, Chad, Mali, Niger, and Northern Cameroon (see, figure 1). Thus, Dawanau market was chosen as the central market, which prices are assumed to drive the prices in the rural markets. More than 50 rural markets supply gari to the Kano urban market while more than 40 rural markets supply cassava chips and chunks (Ezedinma et al 2006c), and most of the markets are located in the central and southern states of Benue, Edo, Kaduna, Kogi, Nasarawa, and Taraba in Nigeria. This paper focuses on the major rural markets that supply traditional cassava products namely gari (yellow and white), cassava chips and cassava chunks to the Dawanau market in Kano. To be precise, the lhugh market in Benue State, Irrua market in Edo State, Agyaragu market in Nasarawa State and Kwesati market in Taraba State represent the rural satellite markets.

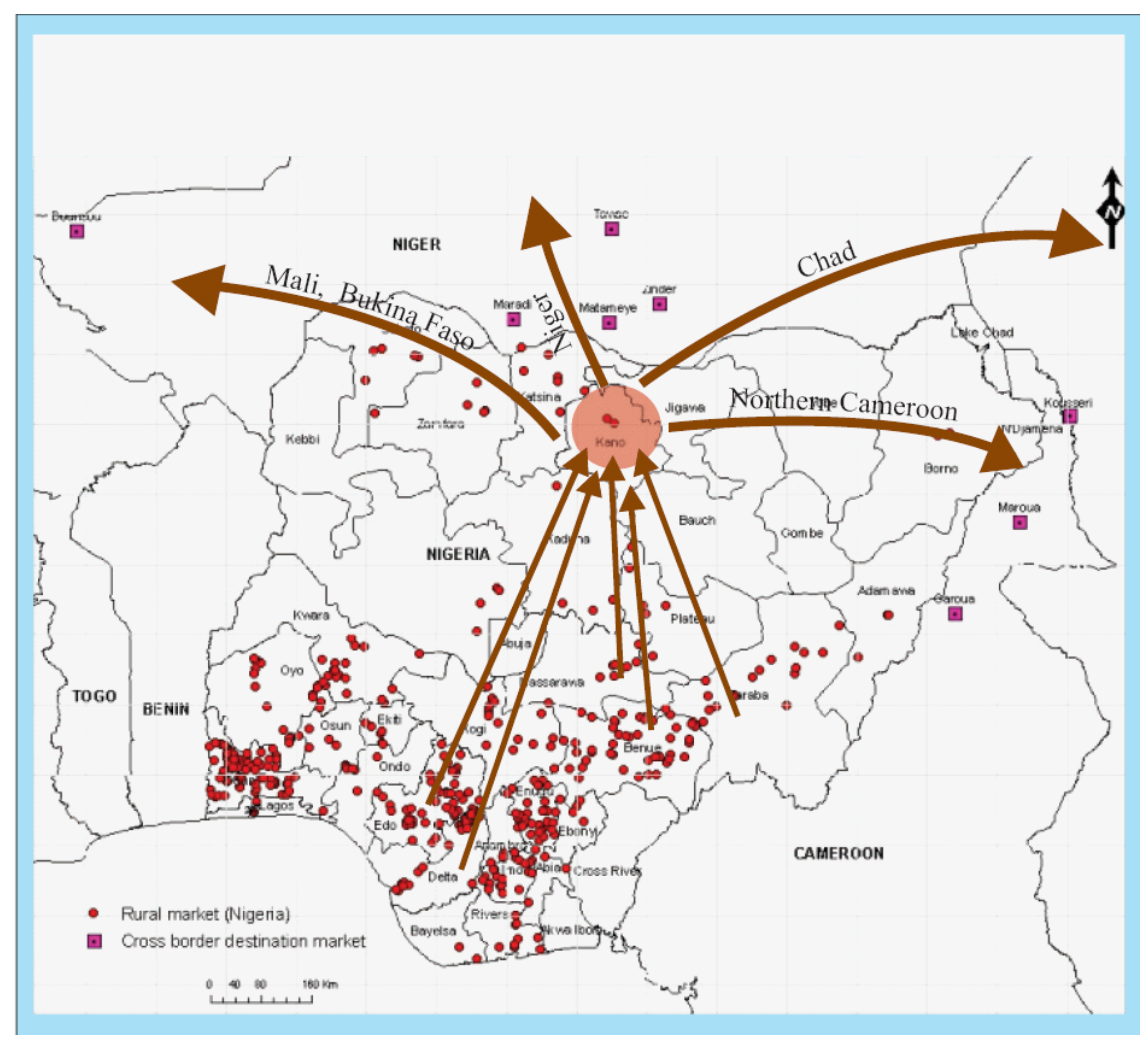

Figure1: Cross Border trade in Gari and Chips: supply and demand zones to Dawanau market, Kano 


\section{Analytical methods}

The study made use of co-integration and its implied error correction model in data analysis. Particularly, the Johansen's method of co-integration which results in the vector error correction model (VECM) was used, due to the possibility of the presence of joint determination between the modelled price series. This approach was necessary because according to Asche et al (2005), when investigating relationships between prices in market integration analysis it is well known that there is in general a simultaneity problem, as economic theory does not always give final answers to which variable is exogenous. In addition, when the price series are non-stationary the Johansen test is the natural approach.

The vector error correction model derives from the vector auto-regression (VAR) model developed by Sims (1980). Thus, the vector error correction model characterises the estimation of co-integrating relationships from a system of co-integrating vectors using the Maximum Likelihood method proposed by Johansen and Juselius (1990) and Johansen (1991), as opposed to the two-step methodology of co-integration postulated by Engle and Granger (1987).

\section{Model Specification}

In this study, we specify a model relating prices of cassava products in rural or peripheral markets to their respective prices in a central market based on the central market hypothesis of geographical markets. The basic assumption in this model is that rural/peripheral market prices are driven by the prices, which prevail in the central market. Thus, in effect, we relax the assumption of a possibility of leading prices from the rural/peripheral markets, although in market integration, as observed by Goodwin and Holt (1999), there are no clear trends, as in some cases, there are leading prices, while in others there are not. In relaxing this assumption, the analysis bypasses the use of Granger-causality tests.

It is hypothesized that within the model, the rural market price (RMP) and the central market price (CMP) are jointly determined while any other variable is exogenous to the system. Given this condition, the vector auto-regression (VAR) representation of our model involving two endogenous variables, without any exogenous variable, following Sims' (1980) can be specified as:

$Z_{t}=\delta+A_{1} Z_{t-1}+A_{2} Z_{t-2}+\ldots+A_{P-1} Z_{t-P+1}+U_{t}$

Where:

$Z_{t}$ is a $(n \times 1)$ vector of non-stationary $I(1)$ endogenous variables;

$\delta$ is a $(n \times 1)$ vector of parameters;

$A_{i}$ are $(n \times n)$ matrix of parameters;

$U_{t}$ is an $(n \times 1)$ vector of random variables, distributed as white noise.

From the above specification,

$\left.Z_{t}=\left[\operatorname{LnRMP} P_{t} \operatorname{LnCMP}\right]_{t}\right]^{\prime}$

Where:

$\mathrm{LnRMP}_{\mathrm{t}}$ is rural market price; and

$\mathrm{LnCMP}_{\mathrm{t}}$ is central market price.

Since we want to distinguish between stationarity by linear combinations and by differencing, the VAR in equation (1) can be re-written in its vector error correction form thus:

$$
\Delta Z_{t}=\delta+\Gamma_{1} \Delta Z_{t-1}+\Gamma_{2} \Delta Z_{t-2}+\ldots+\Gamma_{P-1} \Delta Z_{t-P+1}+\Pi Z_{t-P}+U_{t}
$$

Where:

$Z_{\mathrm{t}}$ is a vector of non-stationary $\mathrm{I}(1)$ endogenous variables; such that $\Delta Z_{t}=Z_{t}-Z_{t-1}$;

$\Pi$ and $\Gamma_{\mathrm{i}}$ are $(\mathrm{n} \times \mathrm{n})$ matrices of parameters with $\Gamma_{i}=-\left(I-A_{1}-A_{2}-\ldots A_{i}\right) ;(i=1, \ldots k-1)$ and $\Pi=I-\Pi_{1}-\Pi_{2} \ldots \Pi \Pi_{k}$.

From the above specification, the information about the short-run and long-run adjustments to the changes in $Z_{t}$ through the estimates of $\Gamma_{i}$ and $\Pi$ respectively can be obtained.

The $\Pi$ matrix in equation 2 , which is termed the long-run impact matrix of the error correction mechanism, is of primary importance. First the rank of $\Pi$ provides the basis for determining the existence of co-integration or long-run relationship between variables. According to Johansen (1988) there are three possibilities with regard to the rank of $\Pi$ :

if $\operatorname{rank}(\Pi)$ is zero, then the variables are not cointegrated and the model is equivalent to a VAR in first differences; if $0<\operatorname{rank}(\Pi)<\mathrm{n}$, then the variables are cointegrated; and if the $\operatorname{rank}(\Pi)=\mathrm{n}$, then the variables are stationary and the model is equivalent to a VAR in levels.

Second, since the term $\Pi \mathrm{Z}_{\mathrm{t}-\mathrm{k}}$ provides information about the long-run equilibrium relationship (co-integrating relationship) between the variables in $\mathrm{Z}_{\mathrm{t}}$, the $\Pi$ matrix can be decomposed into the product of matrices $\alpha$ and $\beta$, that is, $\Pi=\alpha \beta$. Where $\alpha$ is the matrix of speed of adjustment coefficients which characterises the long-run dynamics of the system, while $\beta$ is the matrix representing the $c$-ointegrating relations in which $\beta Z_{t}$ (the disequilibrium error) is stationary (see for example, Johansen and Juselius, 1990; Chang and Griffith, 1998). A large value of $\alpha$ means that the system will respond to a deviation from long-run equilibrium very quickly (that is, with a rapid adjustment) and vice versa.

Given the above vector error correction model in equation (2), the long-run co-integrating equation for the rural market price can be written as:

$L n R M P_{t}=\phi_{0}+\phi_{1} \operatorname{LnCMP}+\varepsilon_{t}$

Where:

$\phi_{0}$ is a constant term that captures transportation costs and quality differences;

$\phi_{1}$ is the long-run static coefficient which gives the relationship between the prices (i.e. the price transmission elasticity); and

$\varepsilon_{t}$ is the random term with the usual stochastic assumptions.

Generally, if $\phi_{1}=0$, there is no relationship between the prices; while if $\phi_{1}=1$, the Law of One Price (LOP) holds, and the relative price is constant. In this case, the goods in question are perfect substitutes. If $0<\phi_{1}<1$ (indicating a positive partial relationship), there is a relationship 
between the prices, but the relative price is not constant and the goods will be imperfect substitutes. If $0>\phi_{1}<1$ (indicating a negative partial relationship), there is a relationship which indicates that the goods are complements.

\section{Model Implementation Techniques}

The study adopts the Johansen Maximum Likelihood procedure of co-integration. In this method, a preliminary analysis is carried out, first, to assess the order of integration of the data series through the use of unit root tests after which we test for the existence of cointegrating (long-run equilibrium) relationships among the data series. If a valid co-integrating relationship is found, then we estimate a vector error correction model; co-integration being a pre-condition for the estimation of an error correction model. For a detailed explanation of conducting unit root and co-integration tests, refer to (Adam, 1992; Tambi, 1999; Niemi, 2003, Nkang et al, 2007).

Once cointegration is established, the vector error correction model of the form given below can be estimated.

$$
\begin{aligned}
& \Delta R M P_{t}=\delta_{10}+\sum_{i=1}^{n} \delta_{11 i} \Delta R M P_{t-i}+\sum_{i=1}^{n} \delta_{12 i} \Delta C M P_{t-i}-\alpha_{13}\left(R M P_{t-1}-C M P_{t-1}\right)+U_{t} \\
& \Delta C M P_{t}=\delta_{20}+\sum_{i=1}^{n} \delta_{21 i} \Delta R M P_{t-i}+\sum_{i=1}^{n} \delta_{22 i} \Delta C M P_{t-i}-\alpha_{23}\left(R M P_{t-1}-C M P_{t-1}\right)+U_{t}
\end{aligned}
$$

Where all the variables are as earlier defined and $\Delta$ is the first difference operator while $\delta_{11}$ to $\delta_{22}$ are short-run coefficients and $\alpha_{13}$ and $\alpha_{23}$ is the error correction mechanism which measures the speed of adjustment from short-run disequilibria to long-run steady-state equilibrium. $U_{t}$ is the error term assumed to be distributed as white noise. All the estimations were performed using the Standard Version of Eviews Econometric Software.

\section{RESULTS AND DISCUSSION}

\section{Time Series Characteristics of Data (Unit Root Tests)}

Table 1 shows the results of unit root (stationarity) test of the entire price series used in the estimations. For all the series in level form (except in the price of chips in Benue) the null hypothesis of the presence of a unit root (that is non-stationarity) cannot be rejected, as it is clear that the critical ADF values are larger in absolute terms than their respective calculated values. On application of the ADF test on their first differenced terms, they become stationary as indicated by the t-values of the ADF test which are larger (in absolute terms) than the standard critical values. Thus we reject the null hypothesis of presence of a unit root. The result indicates that all the price variables (except that of chips in Benue) are integrated of order 1 that is, are I(1), suggesting that there is a possibility for their linear combination to be stationary or co-integrated, that is integrated of order 0 , that is $\mathrm{I}(0)$ (see Engle and Granger, 1987).

Consequently, we proceeded to test for cointegrating relationships using the log-level form of the price series. We estimated bivariate co-integrating relations between each of the rural prices and the central market price to enable us see how the individual prices co-move in the long-run, since a multivariate system may lead to the problem of dimensionality and a loss of information about the speed of price transmission for each of the price series from one market to the other (see for instance, Asche et al, 2005; Johansen and Juselius, 1991).

Table 1: Augmented Dickey Fuller (ADF) Unit Root Test for Prices of Cassava Chips, Chunks, White Gari and Yellow

\begin{tabular}{|c|c|c|c|c|c|}
\hline Variable & \multirow[t]{2}{*}{ ADF statistic } & \multirow{2}{*}{$\begin{array}{c}\text { Critical } \\
\text { value }\end{array}$} & Variable & \multirow[t]{2}{*}{ ADF statistic } & \multirow{2}{*}{$\begin{array}{l}\text { Critical } \\
\text { Value }\end{array}$} \\
\hline Level & & & First Difference & & \\
\hline \multicolumn{6}{|c|}{ Cassava Chips } \\
\hline LnChipsK & -2.040 & $-2.895^{*}$ & $\Delta$ LnChipsK & -12.770 & $-2.895^{*}$ \\
\hline LnChipsT & -2.346 & $-2.895^{*}$ & $\Delta$ LnChipsT & -9.595 & $-2.895^{*}$ \\
\hline LnChipsB & -4.405 & $-2.895^{\star}$ & $\Delta$ LnChipsB & -9.770 & $-2.895^{\star}$ \\
\hline \multicolumn{6}{|c|}{ Cassava Chunks } \\
\hline LnChunksK & -2.7668 & $-2.8959^{*}$ & $\Delta$ LnChunksK & -5.8495 & $-2.8963^{*}$ \\
\hline LnChunksT & -2.4592 & $-2.8967^{*}$ & $\Delta$ LnChunksT & -6.1420 & $-2.8972^{*}$ \\
\hline LnChunksB & -0.0324 & $-2.8959^{*}$ & $\Delta$ LnChunksB & -8.0092 & $-2.8959^{*}$ \\
\hline LnChunksN & -1.8008 & $-2.8951^{*}$ & $\Delta$ LnChunksN & -11.6742 & $-2.8955^{*}$ \\
\hline \multicolumn{6}{|l|}{ White Gari } \\
\hline LnWgariK & -1.4926 & $-3.5073^{* *}$ & $\Delta$ LnWgariK & -13.8704 & $-3.5083^{* *}$ \\
\hline LnWgariT & -3.2175 & $-3.5073^{* *}$ & $\Delta$ LnWgariT & -9.2802 & $-3.5073^{* *}$ \\
\hline LnWgariB & -3.0423 & $-3.5083^{\star *}$ & $\Delta$ LnWgariB & -10.2915 & $-3.5092^{\star *}$ \\
\hline LnWgariN & -1.4906 & $-3.5073^{* *}$ & $\Delta$ LnWgariN & -11.3992 & $-3.5083^{* *}$ \\
\hline LnWgariE & -2.7184 & $-3.5073^{* *}$ & $\Delta$ LnWgariE & -11.6559 & $-3.5083^{* *}$ \\
\hline$Y$ & & & & & \\
\hline
\end{tabular}
Gari in Kano (K), Taraba (T), Benue (B) Nasarawa (N) and Edo (E) 


\begin{tabular}{|l|l|l|l|l|l|}
\hline LnYgariK & -2.1968 & $-3.5073^{* *}$ & $\Delta$ LnYgariK & -10.3526 & $-3.5083^{* *}$ \\
\hline LnYgariT & -3.2064 & $-3.5073^{* *}$ & $\Delta$ LnYgariT & -9.2797 & $-3.5073^{* *}$ \\
\hline LnYgariB & -1.7433 & $-3.5092^{* *}$ & $\Delta$ LnYgariB & -10.3808 & $-3.5092^{* *}$ \\
\hline LnYgariN & -1.6711 & $-3.5073^{* *}$ & $\Delta$ LnYgariN & -12.7729 & $-3.5083^{* *}$ \\
\hline LnYgariE & -1.9311 & $-3.4956^{* *}$ & $\Delta$ LnYgariE & -5.5467 & $-3.5014^{* *}$ \\
\hline
\end{tabular}

Critical values of ADF tests are based on MacKinnon (1996) one-sided p-values. Lag length selection is automatic based on Eviews' Schwarz Information Criteria. $\left({ }^{*}\right),\left({ }^{* *}\right)$ denote $5 \%$ and $1 \%$ critical values respectively

\section{Tests for Cointegration}

Table 2 shows the results of the co-integrating tests on a pair-wise basis. We employed the Johansen Maximum Likelihood method, which uses the trace test and maximal-eigen value test statistics to determine the rank $r$, of the long-run impact matrix $\Pi$ of the error correction mechanism. Results of the trace and maximal-eigen value test indicate that co-integration exist among all the bivariate co-integration equations modelled except for chips between Kano and Benue, white gari between Kano and Nasarawa, yellow gari between Kano and Benue, and Yellow gari between Kano and Edo. This implies that since the prices are cointegrated, the system can be expected to respond to exogenous shocks and return to equilibrium after a while. In order words, prices in any of the rural markets can drift away from the central market price for a while, but would definitely return to equilibrium in the long-run.

Specifically, our results for prices of chips between Kano and Benue, white gari between Kano and Nasarawa, yellow gari between Kano and Benue, and yellow gari between Kano and Edo that show no evidence of co-integration might be indicating that the central market hypothesis has failed in this cases, as there may be a possibility of leading prices in the opposite direction, or even between these four rural markets and some other markets that have not been investigated in this study. Thus, we can infer based on the results that while all other markets are integrated, these four were not.

Table 2: Bivariate Co-integration Tests between Kano and each of the satellite markets

\begin{tabular}{|c|c|c|c|c|c|c|}
\hline Null Hypothesis & $\begin{array}{l}\text { Trace } \\
\text { statistic }\end{array}$ & $\begin{array}{l}5 \% \\
\text { Critical } \\
\text { Value }\end{array}$ & $\begin{array}{l}1 \% \\
\text { Critical } \\
\text { Value }\end{array}$ & $\begin{array}{l}\text { Max-eigen } \\
\text { statistic }\end{array}$ & $\begin{array}{l}5 \% \\
\text { Critical } \\
\text { Value }\end{array}$ & $\begin{array}{l}1 \% \\
\text { Critical } \\
\text { Value }\end{array}$ \\
\hline \multicolumn{7}{|l|}{ Chips } \\
\hline \multicolumn{7}{|l|}{ Kano and Taraba } \\
\hline$r=0$ & 16.447 & 12.53 & 16.31 & 16.362 & 11.44 & 15.69 \\
\hline$r \leq 1$ & $0.0850^{* *}$ & 3.84 & 6.51 & $0.0850^{* *}$ & 3.84 & 6.51 \\
\hline \multicolumn{7}{|l|}{ Kano and Benue } \\
\hline$r=0$ & 9.8814 & 15.41 & 20.04 & 9.5309 & 14.07 & 18.63 \\
\hline$r \leq 1$ & 0.3504 & 3.76 & 6.65 & 0.3504 & 3.76 & 6.65 \\
\hline \multicolumn{7}{|l|}{ Chunks } \\
\hline \multicolumn{7}{|l|}{ Kano and Taraba } \\
\hline$r=0$ & 22.425 & 15.41 & 20.04 & 18.842 & 14.07 & 18.63 \\
\hline$r \leq 1$ & $3.584^{* *}$ & 3.76 & 6.65 & $3.584^{* *}$ & 3.76 & 6.65 \\
\hline \multicolumn{7}{|l|}{ Kano and Benue } \\
\hline$r=0$ & 21.508 & 15.41 & 20.04 & 21.506 & 14.07 & 18.63 \\
\hline$r \leq 1$ & $0.0019^{* *}$ & 3.76 & 6.65 & $0.0019^{* *}$ & 3.76 & 6.65 \\
\hline \multicolumn{7}{|c|}{ Kano and Nasarawa } \\
\hline$r=0$ & 29.635 & 25.32 & 30.45 & 27.099 & 18.96 & 23.65 \\
\hline$r \leq 1$ & $2.536^{*}$ & 12.25 & 16.26 & $2.536^{* *}$ & 12.25 & 16.26 \\
\hline \multicolumn{7}{|l|}{ White Gari } \\
\hline \multicolumn{7}{|l|}{ Kano and Taraba } \\
\hline$r=0$ & 15.8277 & 15.41 & 20.04 & 12.109 & 14.07 & 18.63 \\
\hline$r \leq 1$ & $3.718^{*}$ & 3.76 & 6.65 & 3.7186 & 3.76 & 6.65 \\
\hline \multicolumn{7}{|l|}{ Kano and Benue } \\
\hline$r=0$ & 24.0049 & 15.41 & 20.04 & 21.588 & 14.07 & 18.63 \\
\hline$r \leq 1$ & $2.4162^{* *}$ & 3.76 & 6.65 & $2.4162^{* *}$ & 3.76 & 6.65 \\
\hline \multicolumn{7}{|c|}{ Kano and Nasarawa } \\
\hline$r=0$ & 8.9167 & 15.41 & 20.04 & 6.6799 & 14.07 & 18.63 \\
\hline$r \leq 1$ & 2.2367 & 3.76 & 6.65 & 2.2367 & 3.76 & 6.65 \\
\hline \multicolumn{7}{|l|}{ Kano and Edo } \\
\hline$r=0$ & 23.303 & 15.41 & 20.04 & 21.565 & 14.07 & 18.63 \\
\hline$r \leq 1$ & $1.737^{\star \star}$ & 3.76 & 6.65 & $1.737^{* *}$ & 3.76 & 6.65 \\
\hline \multicolumn{7}{|l|}{ Yellow Gari } \\
\hline \multicolumn{7}{|c|}{ Kano and Taraba } \\
\hline$r=0$ & 21.006 & 15.41 & 20.04 & 15.21 & 14.07 & 18.63 \\
\hline$r \leq 1$ & $5.7869^{* *}$ & 3.76 & 6.65 & 5.7869 & 3.76 & 6.65 \\
\hline \multicolumn{7}{|l|}{ Kano and Benue } \\
\hline$r=0$ & 14.934 & 15.41 & 20.04 & 9.21 & 14.07 & 18.63 \\
\hline
\end{tabular}




\begin{tabular}{|l|l|l|l|l|l|l|l|}
\hline $1 \mathrm{r} \leq 1$ & 5.723 & 3.76 & 6.65 & 5.723 & 3.76 & 6.65 \\
\hline Kano and Nasarawa \\
\hline $\mathrm{r}=0$ & 22.603 & 15.41 & 20.04 & 19.931 & 14.07 & 18.63 \\
\hline $1 \mathrm{r} \leq 1$ & $2.6722^{* *}$ & 3.76 & 6.65 & $2.6722^{* *}$ & 3.76 & 6.65 \\
\hline Kano and Edo & 12.7809 & 15.41 & 20.04 & 9.856 & 14.07 & 18.63 \\
\hline $\mathrm{r}=0$ & 2.9244 & 3.76 & 6.65 & 2.9244 & 3.76 & 6.65 \\
\hline $1 \mathrm{r} \leq 1$
\end{tabular}

$\left({ }^{*}\right),\left({ }^{* *}\right)$ denote cointegration at $5 \%$ and $1 \%$ significance levels respectively.

\section{Vector Error Correction Estimates}

Table 3 shows the summary results of the longrun estimates of price transmission elasticities and speed of price transmission coefficients for each of the pair-wise vector error correction equations. From the results in the table, the estimated price transmission elasticity between Taraba and Kano for chips prices is approximately 1 . This shows that the law of one price (LOP) holds because there is full transmission of prices from the central market. Clearly the relative price between these two markets is constant. Thus there is a constant return in prices implying that a $1 \%$ increase in Kano prices will lead to a $1 \%$ increase in Taraba prices. Furthermore, the speed of adjustment to disequilibrium error is -0.1146 and indicates a feedback of only about $11.46 \%$ of the previous week's disequilibrium from the long-run elasticity of Kano prices for chips. Particularly, this shows that the speed at which Taraba chips prices adjust to changes in Kano prices in an effort to achieve long-run static equilibrium is $11.46 \%$.

For chunks, the price transmission elasticity between Taraba and Kano, Benue and Kano, and Nasarawa and Kano are respectively $-1.1 .24,-0.4348$ and -1.0823 , while the speed of adjustment coefficients are $-0.2678,-0.4619$ and -1.1012 respectively. These results indicate that while there is full price transmission from Kano to Taraba and Nasarawa, transmission is not full for Benue. Beyond these the ECMs indicate a feed back of about $26.78 \%$ and $46.19 \%$ respectively of the previous week's disequilibrium from the long-run elasticity of Kano prices for chunks in Taraba and Benue respectively. In spite of the over-reaction of the ECM between Kano and Nassarawa, it turned out insignificant at the $5 \%$ level of probability or less.

Results for white gari show that the price transmission elasticity between Taraba and Kano, Benue and Kano, Nasarawa and Kano, and Edo and Kano are respectively $-0.4301,-0.5282,-1.5809$ and 0.5627 , while the speed of transmission coefficients are $-0.4157,-0.4715,-0.1578$ and -0.1645 respectively. Recall that the prices between Kano and Nasarawa for white gari were not cointegrated (just like those for Kano and Benue chips) probably because Kano may not be the leading price which is why the transmission elasticity is much greater than one. However, for Taraba, Benue and Edo, we notice that the LOP does not hold for these markets as it concerns white gari. This clearly signals inefficiencies between the central and peripheral markets, which may lead to welfare losses in the marketing chain. Interestingly, the low price transmission elasticities are corroborated with very low speed of transmission coefficients of less than $20 \%$ for each of the three cases in discussion. Particularly, we notice that the speed at which the price of white gari in Taraba, Benue and Edo adjust to changes in Kano prices in an attempt to attain long-run static equilibrium is $14.57 \%$, $15.78 \%$ and $16.45 \%$ respectively, indicating very low price information transfer within one week.

Table 3: Summary Results of the Estimates of the Long-run Parameters (Price Transmission Elasticities and Speed of Price Transmission Coefficients)

\begin{tabular}{|c|c|c|c|}
\hline & Estimated $\phi s$ & Estimated $\alpha s$ (ECMs) & Constant \\
\hline \multicolumn{4}{|l|}{ Chips } \\
\hline Taraba/Kano & $\begin{array}{l}-1.0448^{\star *} \\
(-3.837)\end{array}$ & $\begin{array}{l}-0.1146^{*} \\
(-2.1197)\end{array}$ & 1.0457 \\
\hline Benue/Kano & $\begin{array}{l}-3.4694^{* *} \\
(-4.5479)\end{array}$ & $\begin{array}{l}-0.0278 \\
(-1.0170)\end{array}$ & 10.430 \\
\hline \multicolumn{4}{|l|}{ Chunks } \\
\hline Taraba/Kano & $\begin{array}{l}-1.124^{* *} \\
(-6.5487)\end{array}$ & $\begin{array}{l}-0.2678^{* *} \\
(-3.0663)\end{array}$ & 1.1087 \\
\hline Benue/Kano & $\begin{array}{l}-0.4348^{* *} \\
(-6.5433)\end{array}$ & $\begin{array}{l}-0.4619^{* *} \\
(-4.6303)\end{array}$ & -2.1942 \\
\hline Nasarawa/Kano & $\begin{array}{l}-1.0823 \\
(-1.5559)\end{array}$ & $\begin{array}{l}-0.1012 \\
(-1.5100)\end{array}$ & 0.4212 \\
\hline \multicolumn{4}{|l|}{ White Gari } \\
\hline Taraba/Kano & $\begin{array}{l}-0.4301 \\
(-1.1830)\end{array}$ & $\begin{array}{l}-0.1457^{* *} \\
(-3.4749)\end{array}$ & -1.625 \\
\hline Benue/Kano & $\begin{array}{l}-0.5282^{*} \\
(-2.6911)\end{array}$ & $\begin{array}{l}-0.4715^{\star *} \\
(-3.8746)\end{array}$ & -1.3347 \\
\hline Nasarawa/Kano & $\begin{array}{l}-1.5809^{* *} \\
(-5.8231)\end{array}$ & $\begin{array}{l}-0.1578^{*} \\
(-2.4165)\end{array}$ & 2.4804 \\
\hline Edo/Kano & $-0.5627^{* *}$ & $-0.1645^{\star *}$ & -1.4295 \\
\hline
\end{tabular}




\begin{tabular}{|c|c|c|c|}
\hline & $(-3.4862)$ & $(-4.0705)$ & \\
\hline \multicolumn{4}{|l|}{ Yellow Gari } \\
\hline Taraba/Kano & $\begin{array}{l}-0.4376^{*} \\
(-2.011)\end{array}$ & $\begin{array}{l}-0.1625^{* *} \\
(-3.5357)\end{array}$ & -1.5164 \\
\hline Benue/Kano & $\begin{array}{l}-0.8753^{* *} \\
(-3.633)\end{array}$ & $\begin{array}{l}-0.1553^{* *} \\
(-2.7352)\end{array}$ & 0.1196 \\
\hline Nasarawa/Kano & $\begin{array}{l}-1.051^{* *} \\
(-11.2913)\end{array}$ & $\begin{array}{l}-0.3287^{* *} \\
(-4.0032)\end{array}$ & 1.4004 \\
\hline Edo/Kano & $\begin{array}{l}-1.0396^{* *} \\
(-4.7108)\end{array}$ & $\begin{array}{l}-0.1166^{*} \\
(-2.5751)\end{array}$ & 0.7192 \\
\hline
\end{tabular}

The results for yellow gari indicate that the price transmission elasticity between Taraba and Kano, Benue and Kano, Nasarawa and Kano and Edo and Kano are respectively $-0.437,-0.875,-1.051$, and 1.039 , while their respective speed of transmission coefficients are $-0.1625,-0.1553$,

-0.3287 and -0.1166 . Although the markets for yellow gari in Benue and Edo failed to cointegrate with the Kano market, there is evidence of full price transmission between Kano and the two markets based on their respective price transmission elasticities. Also the Nasarawa market indicates that the LOP holds, and that the relative prices between Nasarawa and Kano are constant. The only exception is the Taraba market which has a less than $50 \%$ price transmission elasticity indicating that there are price transmission problems between Kano and Taraba Yellow gari markets, as is the case with white gari. The speed of transmission coefficients makes sense for only cointegrated markets, thus we highlight only on the error correction mechanisms for Taraba and Kano and Nasarawa and Kano which indicate a feed back of about $16.25 \% 5$ and $32.87 \%$ respectively of the previous week's disequilibrium from the long-run elasticity of Kano prices.

\section{CONCLUSION AND POLICY IMPLICATIONS}

The results of this paper have shown that there is some degree of market efficiency in the traditional cassava food market in Nigeria. Since some cassava commodity prices were co-integrated, the system can be expected to respond to exogenous shocks. Such shocks may be irreversible if they arise from increased demand resulting from the evolving industrial raw materials/export market. This may distort the local market economy and may lead to food insecurity since the industrial market will compete with the traditional market for the same raw material. Thus, the development of the evolving cassava industrial raw material/export sub-sector has to be independent of the traditional market to a large extent. A dual policy approach is therefore recommended. On the one hand, since the results have shown that the speed of price adjustment between the traditional markets is very low and that some of the markets only show weak price transmission, it follows that information flow within the system is not perfect. In view of this, to make the traditional system competitive, the efficiency of the system should be enhanced by better information flow through good road networks and other means of communication e.g. rural telephony using Global System of Mobile Communication (GSM). On the other hand, the evolving industrial/export market should establish their own farms and possibly set-up out-grower schemes with producers in the traditional system, and with the existing institutional support systems, competitiveness can be achieved between the two systems with attendant gains.

\section{REFERENCES}

Adam, C. S., 1992. Recent developments in econometric methods: An application to the demand formoney in Kenya. African Economic Research Consortium (AERC), Special Paper 15: $1-52$.

Asche, F., Jaffry, S. and Hartmann, J., 2005. Price transmission and market integration: Vertical and horizontal price linkages for salmon. Centre for the Economics and management of Aquatic Resources, working Paper 1.

Bokanga M and Tewe, O.O., 1995. Cassava: a premium raw material for food, feed, and industrial sectors in Africa pp 54 - 60 in In RSB Ferris (editor) Proceedings of a Post harvest Conference held in Accra Ghana 2 Nov to 1st December 1995, International Institute of Tropical Agriculture, Ibadan, Nigeria

Chang, H.-S., and Griffith, G., 1998. Examining LongRun Relationships between Australian Beef Prices. The Australian Journal of Agricultural and Resource Economics, 42(4): 369-387

Engle, R. F. and C. W. J. Granger, 1987. Co-integration and error correction: representation, estimation and testing. Econometrica, 55(2): 251-276.

Ezedinma C, Dixon, A.G.O., Sanni, L., Okechukwu, R., Akoroda, M., Lemchi, J., Ogbe, F. and Okoro, E., 2006a. Trends in Cassava Production and Commercialisation in Nigeria, International Institute of Tropical Agriculture, Ibadan

Ezedinma C., L Sanni, R Okechukwu and K. Adebayo, $2006 \mathrm{~b}$. Socio economic studies on cross border trade and marketing of cassava products in Nigeria, International Institute of Tropical Agriculture, Ibadan, Nigeria

Ezedinma C. I., Ojiako, I., Lemchi, J., Okechukwu R., Sanni, L., Akoroda, M., Ogbe, F., Okoro, E, and Dixon, A., 2006c. The Cassava Food Commodity Markets and Trade Networks in Nigeria, Draft Report, International Institute of Tropical Agriculture, Ibadan, Nigeria 
Ezedinma C., R Okechukwu, and L Sanni, 2005. Marketing of gari in Benin City and Enugu, Nigeria, In: Investigations on Building a Food Marketing Policy Evidence Base in Nigeria. G Porter and F Lyon (eds) Chapter 7, pp 121-141, http://www.dur.ac.uk/nigerian.marketing/

Goodwin, B. K., and Holt, M. T., 1999. Price Transmission and Asymmetric Adjustment in the U.S. Beef Sector. American Journal of Agricultural Economics 81: 630-637.

Johansen, S. and Juselius, K., 1990, Maximum likelihood estimation and inference on cointegration-with applications to the demand for money. Oxford Bulletin of Economics and Statistics, 52: 169-210.

Johansen, S., 1991. Estmation and Hypothesis Testing of Cointegration Vectors in Gaussian Vector Autoregressive Models. Econometrica, 59, 1551-80.

Johansen, S., 1988. Maximum Likelihood Estimation and Inference on Cointegration with Application to the Demand for Money. Oxford Bulletin of Economics and Statistics, 52(2):160-210.

Knipscheer H., Asumugha, G., Ezedinma, C., Kormawa, P., Makinde, K., Okechukwu, R. and Dixon, A., 2004. Opportunities in the Industrial Cassava Market in Nigeria, A sub sector study, International Institute of Tropical Agriculture, Ibadan, Nigeria.
Niemi, J., 2003. Cointegration and Error Correction Modelling of Agricultural Commodity Trade: The Case of ASEAN Agricultural Exports to the EU. Agriculture and Food Science in Finland, 12: Supplement 1

Nkang, N. M., Abang, S. O., Akpan, O. E. and Offem, K. J., 2007. Price and Income Elasticities of Palm Kernels Exports Supply in Nigeria. Journal of International Food and Agribusiness Marketing, 19(4): 145-157

Nweke F. I., 1995. Processing Cassava for wider market opportunities in Africa pp 45 - 53 In RSB Ferris (editor) Proceedings of a Post harvest Conference held in Accra Ghana 2 Nov to $1^{\text {st }}$ December 1995, International Institute of Tropical Agriculture, Ibadan, Nigeria

Nweke F.I, Spencer, D.S.C. and Lynam, J., 2002. The Cassava Transformation: Africa's Best Kept Secret, Michigan State University Press, East Lansing, Michigan, USA.

Sims, C. A., 1980. Macroeconomics and Reality. Econometrica, 48: 1-49.

Tambi, N. E. 1999. Cointegration and Error Correction Modelling of Export Supply in Cameroon. Agricultural Economics, 20: 57-67. 